\title{
Biogenic Synthesis of Silver Nanoparticles Using Scenedesmus abundans and Evaluation of Their Antibacterial Activity
}

\author{
Nafe Aziz, ${ }^{1}$ Tasneem Fatma, ${ }^{2}$ Ajit Varma, ${ }^{1}$ and Ram Prasad ${ }^{1}$ \\ ${ }^{1}$ Amity Institute of Microbial Technology, Amity University, Noida, Uttar Pradesh 201303, India \\ ${ }^{2}$ Department of Bio-Sciences, Jamia Millia Islamia, Jamia Nagar, New Delhi 110025, India \\ Correspondence should be addressed to Ram Prasad; rpjnu2001@gmail.com
}

Received 6 August 2014; Revised 23 August 2014; Accepted 25 August 2014; Published 14 September 2014

Academic Editor: Amir Kajbafvala

Copyright (c) 2014 Nafe Aziz et al. This is an open access article distributed under the Creative Commons Attribution License, which permits unrestricted use, distribution, and reproduction in any medium, provided the original work is properly cited.

\begin{abstract}
Silver nanoparticle (AgNP) was synthesized using the cell free extract of Scenedesmus abundans with $\mathrm{AgNO}_{3}$. The synthesized silver nanoparticles were characterized by UV-visible spectroscopy, dynamic light scattering (DLS), scanning electron microscopy (SEM), and Photoluminescence. Bioreduction of $\mathrm{Ag}^{+}$ions showed a gradual change in the colour of the extract and nanoparticles were synthesized having the range of $420-440 \mathrm{~nm}$ under UV-visible spectrum. The antibacterial efficacy was assessed against pathogenic bacteria E. coli, Klebsiella pneumoniae, and Aeromonas hydrophila. The present study revealed that the AgNPs prepared from Scenedesmus abundans show antibacterial efficacy against the test pathogens. The bioaccumulation of silver particles makes the organism potential candidate for ecofriendly silver biorecovery system and S. abundans can be used as a source of silver nanoparticles.
\end{abstract}

\section{Introduction}

Nanoparticles are gaining the interest in it due to their unique characteristics such as electronic, mechanical, optical, magnetic, chemical properties $[1,2]$ and high surface to volume ratio which differ significantly with bulk materials $[3,4]$. In nanotechnology, the formation of nanoparticles has the method that mainly involved the process of separation deformation and transformation of materials to atoms or molecules [5]. The synthesis of nanoparticles can occur by different methods such as dry, wet, and through computational nanotechnology. Basically dry nanotechnology concentrates on surface science, physical chemistry, and structure of organic and inorganic materials. Wet nanotechnology deals with biological systems that exist primarily in water base system, such as enzymes, membranes, and cellular components. Computational nanotechnology comprises modelling and stimulation of complex nanometer. The novel metal nanoparticles had attended much interest due to their vast applications in diverse areas such as optoelectronics, cosmetics, photo catalysis, diodes, piezoelectric devices, fluorescent tubes, laser, sensor, photography, biological labeling, photonics coatings, packaging, and drug delivery system [59]. Now a days nanomaterials are produced by industries for commercial application having many benefits. Green synthesis of nanoparticles attracts many researchers and industries. Many microorganisms are utilized for the synthesis of nanoparticles intracellularly as well as extracellularly [10-13]. The mechanism behind the synthesis of silver nanoparticles was not known before but it was hypothesized later that the enzymes $\mathrm{NADH}$-dependent nitrate reductase were used for the reduction of silver ions [14]. Biosynthesis of nanoparticles has been reported by many photoautotrophic microorganisms such as cyanobacteria, eukaryotic algae, and fungi, and even in plants [15-20] there are various other processes such as bioremediation, bioleaching, biological metal recovery, and biomineralization which have been done by biological system [21]. Biologically synthesized nanoparticles have proved to be better than the chemically synthesized nanoparticles due to slower kinetics, which offer a better control over crystal growth and reduced investment involved in production [22]. Among the biological materials, algae could be considered as "bionanofactories" because the live and dead dried biomass can be utilized for synthesis of 
metallic nanoparticles. Both unicellular and multicellular organisms have been known to produce intracellular or extracellular inorganic materials as well as high growth rate and high biomass productivity with a less cultivation time. Besides, they have been proved as a potential organism for heavy metal detoxification and production of commercially important metabolites, including biodiesel production [23]. As algae have diverse groups of organisms and make up the lower phylogenetic echelons of the plant kingdom and contain many characteristics of the higher plants [24]. Algae execute about $50 \%$ of the photosynthesis on earth planet and thus are involved in supporting the biosphere [25]. S. abundans required smaller amount of sunlight, $\mathrm{CO}_{2}$, and minerals for growth, because of these properties it is a suitable organism for the biosynthesis of nanoparticles.

This study reported that the nanoparticles synthesis by using the fresh water green microalga S. abundans extract and characterized by UV-vis spectroscopy and morphological structure which were characterized by SEM. The antimicrobial activity of silver nanoparticles against pathogenic bacteria was studied as well.

\section{Material and Methods}

2.1. Chemicals, Culture, and Growth Conditions. All analytical reagents and media components were purchased from HiMedia (Mumbai, India) and Sigma Chemicals (St. Louis, MO, USA). Scenedesmus abundans (NCIM 2897) culture procured from National Centre for Industrial Microorganism (NCIM), Pune. Culture was grown on Bold's Basal Medium which is composed of $\left(\mathrm{mgL}^{-1}\right)$ : $\mathrm{NaNO}_{3}$ (250), $\mathrm{K}_{2} \mathrm{HPO}_{4}$ (75), $\mathrm{KH}_{2} \mathrm{PO}_{4}$ (175), $\mathrm{CaCl}_{2} \cdot 2 \mathrm{H}_{2} \mathrm{O}$ (25), $\mathrm{MgSO}_{4} \cdot 7 \mathrm{H}_{2} \mathrm{O}(75), \mathrm{NaCl}(25), \mathrm{ZnSO}_{4} \cdot 7 \mathrm{H}_{2} \mathrm{O}$ (882), $\mathrm{MnCl}_{2} \cdot 4 \mathrm{H}_{2} \mathrm{O}$ (144), $\mathrm{Co}\left(\mathrm{NO}_{3}\right)_{2} \cdot 6 \mathrm{H}_{2} \mathrm{O}$ (49), $\mathrm{MoO}_{3}$ (71), $\mathrm{H}_{3} \mathrm{BO}_{3}$ (114), EDTA $\cdot \mathrm{Na}_{2}(500), \mathrm{KOH}(310), \mathrm{FeSO}_{4} \cdot 7 \mathrm{H}_{2} \mathrm{O}$ (498), and conc. $\mathrm{H}_{2} \mathrm{SO}_{4}(1 \mathrm{~mL})$ at $24 \pm 1^{\circ} \mathrm{C}$ in a continuous illumination with cool white fluorescent tubes (Philips $40 \mathrm{~W}$ ) having irradiance of $50 \mathrm{Me} / \mathrm{m}^{2} / \mathrm{s}$ in a $16 \mathrm{~h}: 8 \mathrm{~h}$ light/dark regime. The bacterial pathogens used as E. coli, Klebsiella pneumoniae, and Aeromonas hydrophila were grown on Muller Hinton agar (MHA) at $37^{\circ} \mathrm{C}$ for overnight incubation for further use and stored at $4^{\circ} \mathrm{C}$.

2.2. Biosynthesis of Silver Nanoparticles. Cell free extract was prepared from Scenedesmus abundans for nanoparticle synthesis. It was grown in Bold's basal medium and after 14 days of incubation pellets were separated by centrifugation at $10,000 \mathrm{rpm}$ for 10 minutes and the pellets were washed with sterile double distilled water in order to remove the traces of media. Pellets were dried at $80^{\circ} \mathrm{C}$ and dry weight measurement was done. $1 \mathrm{gm}$ of algal powder into $30 \mathrm{~mL}$ of double distilled water was added and boiled at $100^{\circ} \mathrm{C}$ for 20 minutes in an Erlenmeyer flask then centrifuged at $5000 \mathrm{rpm}$ for $10 \mathrm{~min}$ after cooling. Biosynthesis of AgNP was done by adding $10 \mathrm{~mL}$ of cell free extract in $90 \mathrm{~mL}$ of $1 \mathrm{mM} \mathrm{AgNO}$ and incubated at room temperature for 48 hours. The change in colour indicates AgNP synthesis.
2.3. Characterization of Synthesized Silver Nanoparticles. The bioreduction of AgNPs was monitored using Double Beam UV-Vis spectrophotometer (Labtronics) in $1 \mathrm{~cm}$ path length quartz cuvette having spectral range of 300 and $700 \mathrm{~nm}$ at different time intervals. Dynamic Light Scattering was used to determine hydrodynamic sizes, polydispersities, and aggregation effects of colloidal samples. Size distribution of synthesized AgNPs was measured using a Nano Zetasizer system (Malvern Instruments). The particular parameters used such as measurement temperature of $25^{\circ} \mathrm{C}$, medium viscosity of $0.8872 \mathrm{mPa} \cdot \mathrm{s}$, and material refractive index of 1.59 before measuring the sample were passed through a $0.2 \mu \mathrm{m}$ polyvinylidene fluoride (PVDF) membrane and the sample was loaded into quartz microcuvette, and measurement was performed. Scanning electron microscopy offers the information regarding the shape, size, and surface of the nanoparticles. Electron microscopy images a sample by scanning it with a high-energy beam of electrons. First the sample was sonicated for 15 minutes, then a drop of sample was dried on the glass slide, and this thin film was coated by carbon coated copper grid and observed under ZEISS EVO HD SEM. Photoluminescence spectra were recorded in Shimadzu (Japan) spectrofluorometer using $90^{\circ}$ illumination and performed to find out the excitation and emission maxima for the silver nanoparticles. The excitation and emission slit widths were kept at 10 and $10 \mathrm{~nm}$, respectively. The entire scanning was done at the speed of $600 \mathrm{~nm} / \mathrm{min}$.

2.4. Antimicrobial Property. To study the antibacterial effect of synthesized AgNPs from microalgae, agar well diffusion method was used against E. coli, Klebsiella pneumoniae, and Aeromonas hydrophila. $100 \mu \mathrm{L}$ of bacteria was spread uniformly on MHA plate and $5 \mathrm{~mm}$ diameter wells were made on the medium. Into each well, $25,50,75$, and $100 \mu \mathrm{L}$ concentrations of AgNPs were added and the plates were incubated at $37^{\circ} \mathrm{C}$ for 24 hours and zone of inhibition was measured. Each experiment was performed in triplicate.

\section{Result and Discussion}

3.1. Scenedesmus abundans Mediated Bioreduction of Silver Ions. During bioreduction of AgNPs from silver ions there is a colour change which was monitored by using spectroscopic techniques. In vitro synthesis of AgNPs by S. abundans, it was observed that there is a colour change from colourless to reddish yellow due to the excitation of plasmon vibrations with AgNPs and the absorbance maximum was observed at $420 \mathrm{~nm}$ (Figure 1). The mechanism behind the synthesis of AgNPs was not known before but it was hypothesized later that the enzymes $\mathrm{NADH}$-dependent nitrate reductase were used for the reduction of silver ions. The UV-Vis absorption spectra of AgNPs of $S$. abundans were shown in Figure 1 after 48 hours of the bioreduction.

3.2. Dynamic Light Scattering. The size measured in DLS technique is the hydrodynamic diameter of the theoretical area that diffuses with the similar speed as the measured nanoparticles. This size is not only connected with the 


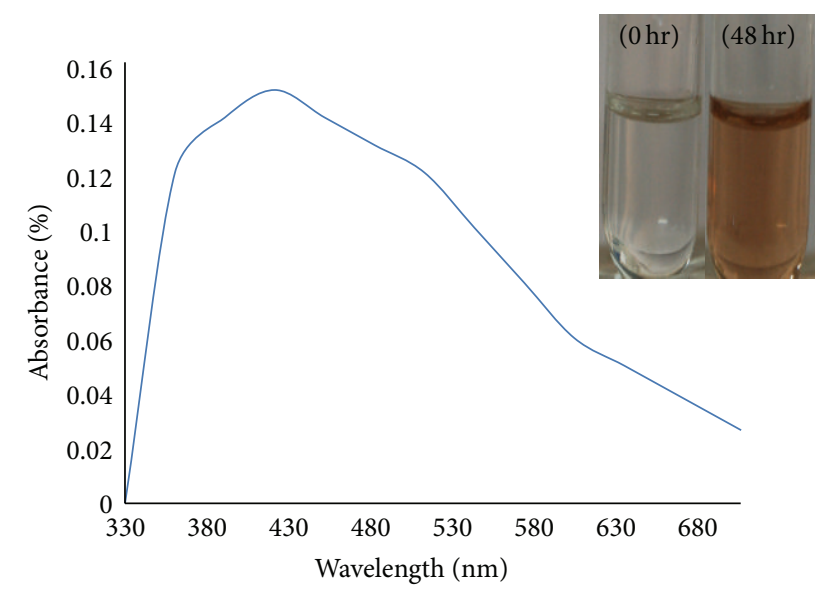

FIGURE 1: UV-Visible spectra of cell free extract after bioreduction.

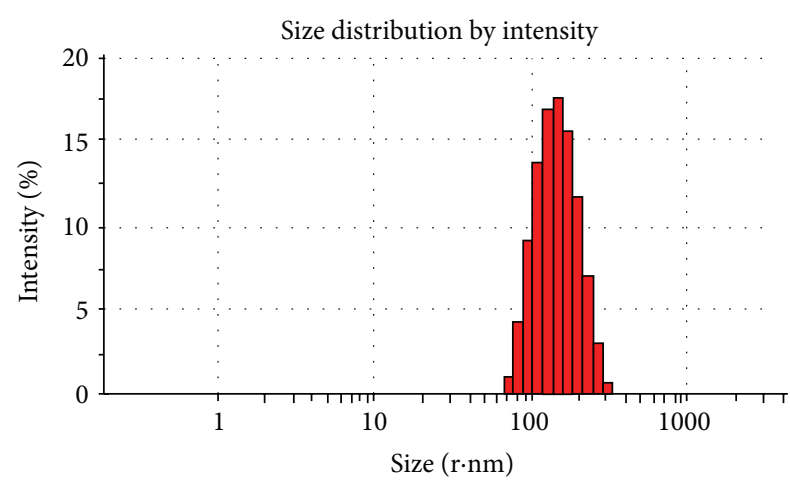

FIGURE 2: DLS spectra of the size distribution profile of the synthesized AgNPs.

metallic core of the nanoparticles but it is also influenced with all substances adsorbed on the surface of the nanoparticles (e.g., stabilizers) and the thickness of the electrical double layer (solvation shell), moving along with the particle. The thickness of the electrical double layer and its influence on the measured size of nanoparticles depend on the substances present in the colloid and on the surface of nanoparticles. As a result, the size measured in DLS technique is bigger in comparison with macroscopic techniques done in order to analyse the size distribution of synthesized nanoparticles with respect to the intensity. It was observed that on in vitro synthesis of nanoparticles the mean average size of the nanoparticles was found to be around $150 \mathrm{~nm}$ as given in Figure 2. The polydispersity index (PDI) of AgNPs was observed to be 0.212 which points out that these particles are polydispersed. Further analysis was done in order to confirm the size and presence of silver nanoparticles.

3.3. Scanning Electron Microscopy. SEM was carried out to analyze the synthesized nanoparticles for the morphology and their size. The SEM micrograph of in vitro bioreduction of silver ions confirms the size of the nanoparticles within the average range of $59-66 \mathrm{~nm}$. The particles are well dispersed and showing no agglomeration as shown in Figure 3.

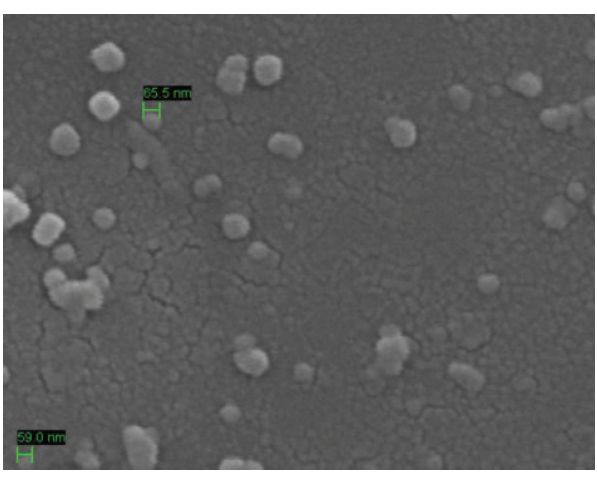

FIgURE 3: SEM image of synthesized AgNPs from S. abundans.

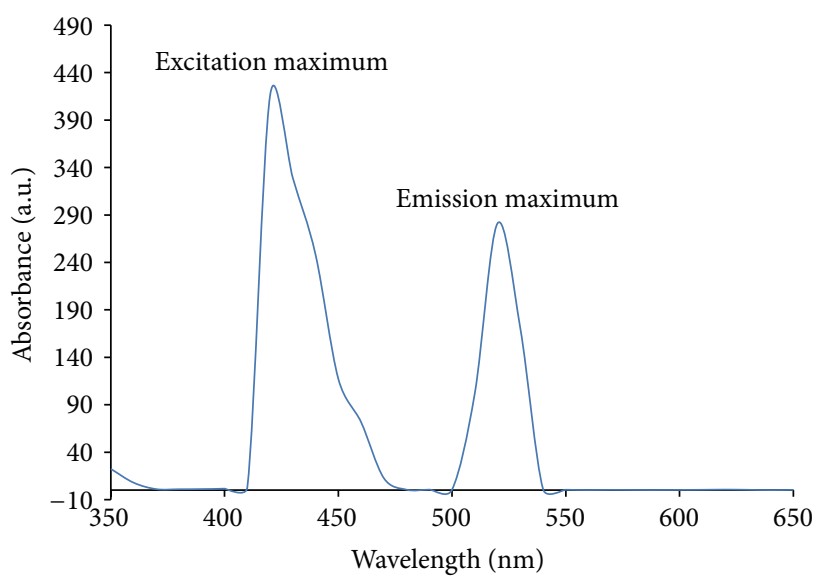

Figure 4: Photoluminescence of AgNPs synthesized from S. abundans.

3.4. Photoluminescence. The data were analyzed using the WINFLR software. The photoluminescence from the roughened surface of noble metals could be viewed as an excitation of electrons from occupied d bands into state above the Fermi level; this mechanism is responsible for the nanocluster photoluminescence. This means that the growth of the clusters and the surface has changed the efficiency of the coupling of the excitation radiation to the surface plasmon. It is also found that there is no photoluminescence for large metal particles, because of them rapid radiation less processes compete effectively with radiative processes. Thus the smaller AgNPs clusters coexisting with the larger AgNPs are mainly responsible for the photoluminescence phenomena [26, 27]. Through analysis it was found that the photoluminescence spectra of synthesized AgNPs show that the excitation peak was found at $420 \mathrm{~nm}$, while the emission peak was observed at $520 \mathrm{~nm}$ (Figure 4). The excitation peak at $420 \mathrm{~nm}$ is very well correlated with the absorption maxima recorded with UV-visible spectrophotometer.

3.5. Antibacterial Activity. Biosynthesized AgNPs were analysed for antibacterial activity against human pathogenic bacteria such as E. coli, Klebsiella pneumonia, and Aeromonas hydrophila. These tests were performed on MHA plates by 


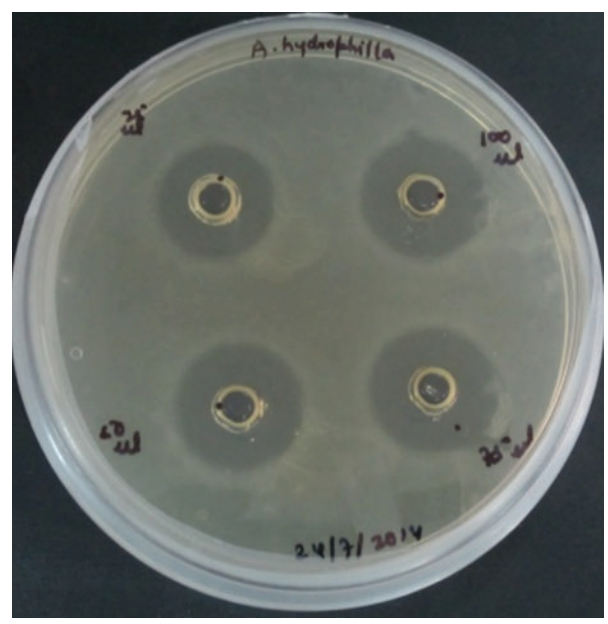

(a)

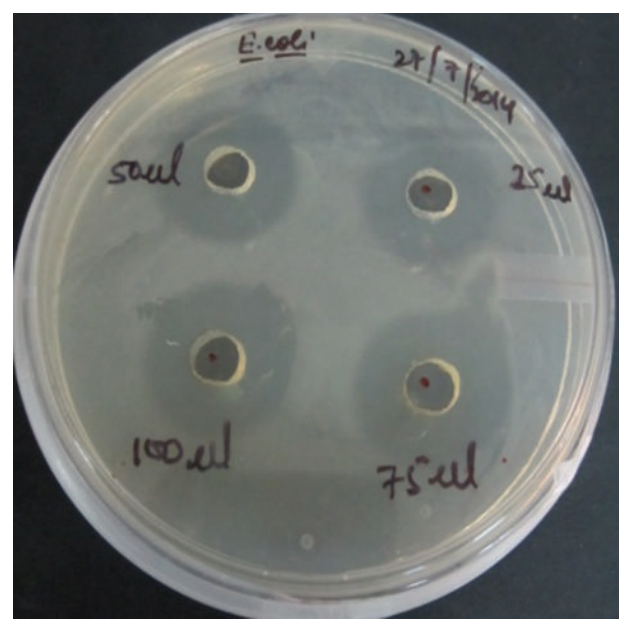

(b)

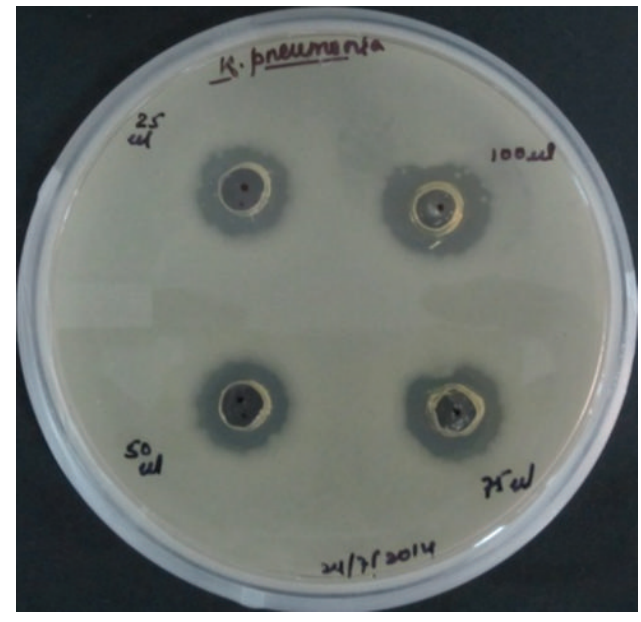

(c)

Figure 5: Antibacterial effects varying the concentrations of AgNPs from $25 \mu \mathrm{L}$ to $100 \mu \mathrm{L}$ against (a) Aeromonas hydrophila, (b) E. coli, and (c) Klebsiella pneumonia.

well-diffusion method [28]. Growth of bacteria was inhibited by AgNPs and forms an inhibitory zone in Figures 5 and 6.

The highest zone of inhibition was observed for E. coli even at lower concentration. The mechanism of inhibition is still unknown. But the possible hypothesis for the mechanism related to the inhibition may be due to ionic binding of the AgNPs on the surface of the bacteria causing increase in the proton motive force; other hypothesis states that the nanoparticles enter into the cell and bind to the enzymes containing thiol groups $[29,30]$. The molecular basis for the biosynthesis of these silver crystals, as the organic matrix contains the properties of silver binding which provides amino acid moieties which serve as the nucleation sites [31, 32]. The nanoparticles produced through in vitro synthesis that is by cell free extract gives zone of inhibition. The bacterial growth inhibition may be dependent upon the concentration of the nanoparticles present in the medium.

During the study S. abundans was utilized for the synthesis of AgNps upon addition of silver ions into the cell free extract. The colour of the samples changed from colourless to

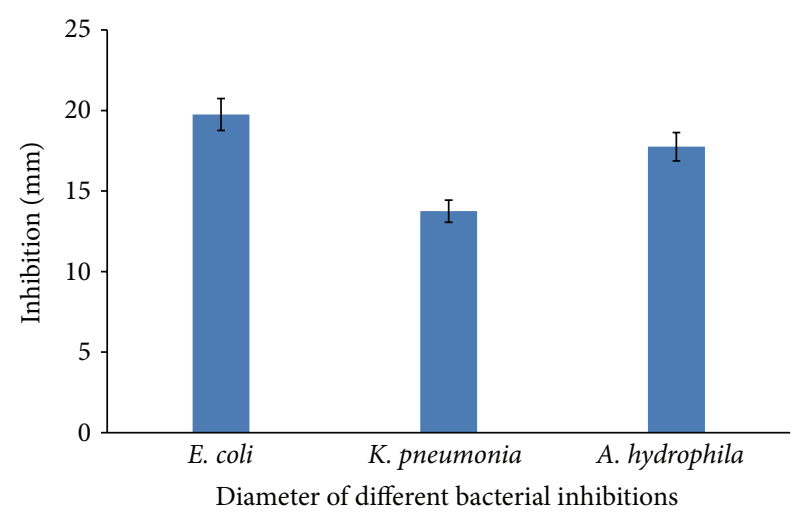

FIGURE 6: Antibacterial activity against synthesized AgNPs from $S$. abundans.

yellowish brown and observed UV-visible spectrum $420 \mathrm{~nm}$ due to reduction of the silver nitrate in aqueous solution 
due to excitation of surface plasmon vibrations in silver nanoparticles. The plasmon bands were observed as broad, due to the size distribution of the particles [33, 34]. The size and structure of nanoparticles were further characterized using DLS and SEM analysis. The surface deposited AgNps are clearly seen at high magnification in the micrograph. Photoluminescence spectra of silver nanoparticles show that the excitation peak was at $420 \mathrm{~nm}$, while the emission peak was observed at $520 \mathrm{~nm}$. The rapid biological synthesis of silver nanoparticles by $S$. abundans provides a simple and proficient route for the synthesis of nanoparticles with optical properties directed by particle size. AgNPs have been verified to exhibit antimicrobial properties against bacteria with close attachment of the nanoparticles with the microbial cell and the action being size dependent [35-37].

\section{Conclusion and Future Prospects}

Biological synthesis of the AgNPs is rapid, cost effective, ecofriendly, and simple method of synthesis. There is lots of work done for green synthesis of nanoparticles from both prokaryotic as well as eukaryotic organisms [38]. During the whole work it has been concluded that the synthesized AgNPs through in vitro bioreduction system from unicellular microalga $S$. abundans produced significant amount of nanoparticles when it is exposed to $1 \mathrm{mM}$ silver nitrate solution. The SEM analysis revealed that size of the nanoparticles ranges from 59 to $66 \mathrm{~nm}$, and the synthesized nanoparticles were well dispersed. These nanoparticles show a broad spectrum of antimicrobial activity against both Gram positive and Gram negative bacteria [39, 40]. There is an everlasting need to increase the development of green synthesis of nanoparticles which should be environmentally acceptable solvent system, ecofriendly reducing and capping agents, high yield, low cost, and nontoxic [41].

Future prospects of this research is to scale up the biosynthesis production of AgNPs using these algae and also with the wide spectrum of microbial population. Further investigations would involve exploring the potency of microalgae to synthesize other metallic nanoparticles that can be used in pharmaceutical, food, cosmetics industry, and therapeutically in biomedical applications.

\section{Conflict of Interests}

The authors declare that there is no conflict of interests regarding the publication of this paper.

\section{Acknowledgments}

The authors are thankful to Dr. VK Jain, Advisor, AIARS (M\&D), Amity University for SEM and Dr. Ravi Mani Tripathi, Assistant Professor, Amity University, India, for critically reading the paper and analyzing the data.

\section{References}

[1] P. Mukherjee, A. Ahmad, D. Mandal et al., "Fungus-mediated synthesis of silver nanoparticles and their immobilization in the mycelial matrix: a novel biological approach to nanoparticle synthesis," Nano Letters, vol. 1, no. 10, pp. 515-519, 2001.

[2] A. Kajbafvala, J. P. Samberg, H. Ghorbani, E. Kajbafvala, and S. K. Sadrnezhaad, "Effects of initial precursor and microwave irradiation on step-by-step synthesis of zinc oxide nanoarchitectures," Materials Letters, vol. 67, no. 1, pp. 342-345, 2012.

[3] A. Kajbafvala, M. R. Shayegh, M. Mazloumi et al., "Nanostructure sword-like $\mathrm{ZnO}$ wires: rapid synthesis and characterization through a microwave-assisted route," Journal of Alloys and Compounds, vol. 469, no. 1-2, pp. 293-297, 2009.

[4] S. Sinha, I. Pan, P. Chanda, and S. K. Sen, "Nanoparticles fabrication using ambient biological resources," Jounal of Applied Biological Science, vol. 19, pp. 1113-1130, 2009.

[5] B. Wiley, Y. Sun, and Y. Xia, "Synthesis of silver nanostructures with controlled shapes and properties," Chemical Research, vol. 40, no. 10, pp. 1067-1076, 2007.

[6] A. Kajbafvala, H. Ghorbani, A. Paravar, J. P. Samberg, E. Kajbafvala, and S. K. Sadrnezhaad, "Effects of morphology on photocatalytic performance of Zinc oxide nanostructures synthesized by rapid microwave irradiation methods," Superlattices and Microstructures, vol. 51, no. 4, pp. 512-522, 2012.

[7] A. Kajbafvala, S. Zanganeh, E. Kajbafvala, H. R. Zargar, M. R. Bayati, and S. K. Sadrnezhaad, "Microwave-assisted synthesis of narcis-like zinc oxide nanostructures," Journal of Alloys and Compounds, vol. 497, no. 1-2, pp. 325-329, 2010.

[8] H. J. Klasen, "A historical review of the use of silver in the treatment of burns. II. Renewed interest for silver," Burns, vol. 26, no. 2, pp. 131-138, 2000.

[9] Y. F. Huang, H. T. Chang, and W. Tan, "Cancer cell targeting using multiple aptamers conjugated on nanorods," Analytical Chemistry, vol. 80, no. 3, pp. 567-572, 2008.

[10] N. Chakraborty, R. Pal, A. Ramaswami, D. Nayak, and S. Lahiri, "Diatom: a potential bio-accumulator of gold," Journal of Radioanalytical and Nuclear Chemistry, vol. 270, no. 3, pp. 645-649, 2006.

[11] D. Parial, H. K. Patra, A. K. R. Dasgupta, and R. Pal, "Screening of different algae for green synthesis of gold nanoparticles," European Journal of Phycology, vol. 47, no. 1, pp. 22-29, 2012.

[12] C. Nethradevi, P. Sivakumar, and S. Renganathan, "Green synthesis of silver nanoparticles using datura metel flower extract and evaluation of their antimicrobial activity," International Journal of Nanomaterials and Biostructures, vol. 2, pp. 16-21, 2012.

[13] R. R. Nayak, N. Pradhan, D. Behera et al., "Green synthesis of silver nanoparticle by Penicillium purpurogenum NPMF: the process and optimization," Journal of Nanoparticle Research, vol. 13, no. 8, pp. 3129-3137, 2011.

[14] D. Vijayaraj, J. Anarkali, K. Rajathi, and S. Sridhar, "Green synthesis and characterization of silver nanoparticles from the leaf extract of aristolochia bracteata and its antimicrobial efficacy," International Journal of Nanomaterials and Biostructures, vol. 2, pp. 11-15, 2012.

[15] A. Saxena, R. M. Tripathi, F. Zafar, and P. Singh, "Green synthesis of silver nanoparticles using aqueous solution of Ficus benghalensis leaf extract and characterization of their antibacterial activity," Materials Letters, vol. 67, no. 1, pp. 91-94, 2012. 
[16] N. Pradhan, R. R. Nayak, A. K. Pradhan, L. B. Sukla, and B. K. Mishra, "In situ synthesis of entrapped silver nanoparticles by a fungus-penicillium purpurogenum," Nanoscience and Nanotechnology Letters, vol. 3, no. 5, pp. 659-665, 2011.

[17] R. G. Haverkamp and A. T. Marshall, "The mechanism of metal nanoparticle formation in plants: limits on accumulation," Journal of Nanoparticle Research, vol. 11, no. 6, pp. 1453-1463, 2009.

[18] V. K. Sharma, R. A. Yngard, and Y. Lin, "Silver nanoparticles: green synthesis and their antimicrobial activities," Advances in Colloid and Interface Science, vol. 145, no. 1-2, pp. 83-96, 2009.

[19] N. Savithramma, M. Linga Rao, K. Rukmini, and P. Suvarnalatha Devi, "Antimicrobial activity of silver nanoparticles synthesized by using medicinal plants," International Journal of ChemTech Research, vol. 3, no. 3, pp. 1394-1402, 2011.

[20] R. Prasad, "Synthesis of silver nanoparticles in photosynthetic plants," Journal of Nanoparticles, vol. 2014, Article ID 963961, 2014.

[21] K. N. Thakkar, S. S. Mhatre, and R. Y. Parikh, "Biological synthesis of metallic nanoparticles," Nanomedicine, vol. 6, no. 2, pp. 257-262, 2010.

[22] K. Vijayaraghavan and S. P. K. Nalini, "Biotemplates in the green synthesis of silver nanoparticles," Biotechnology Journal, vol. 5, no. 10, pp. 1098-1110, 2010.

[23] A. L. Ahmad, N. H. M. Yasin, C. J. C. Derek, and J. K. Lim, "Microalgae as a sustainable energy source for biodiesel production: a review," Renewable and Sustainable Energy Reviews, vol. 15, no. 1, pp. 584-593, 2011.

[24] S. Rajeshkumar, C. Malarkodi, K. Paulkumar, M. Vanaja, G. Gnanajobitha, and G. Annadurai, "Algae mediated green fabrication of silver nanoparticles and examination of its antifungal activity against clinical pathogens," International Journal of Metals, vol. 2014, Article ID 692643, 8 pages, 2014.

[25] H. C. Bold and M. J. Wynne, Introduction to the Algae: Structure and Reproduction, vol. 16, Prentice-Hall, Englewood Cliffs, NJ, USA, 2nd edition, 1985.

[26] P. He, X.-H. Shen, and H.-C. Gao, "Photoluminescence phenomenon during the formation of silver nanoparticles," Acta Physico-Chimica Sinica, vol. 20, no. 10, pp. 1200-1203, 2004.

[27] N. Vigneshwaran, A. A. Kathe, P. V. Varadarajan, R. P. Nachane, and R. H. Balasubramanya, "Biomimetics of silver nanoparticles by white rot fungus, Phaenerochaete chrysosporium," Colloids and Surfaces B: Biointerfaces, vol. 53, no. 1, pp. 55-59, 2006.

[28] R. Prasad, V. S. Swamy, K. S. Prasad, and A. Varma, "Biogenic synthesis of silver nanoparticles from the leaf extract of Syzygium cumini (L.) and its antibacterial activity," International Journal of Pharma and Bio Sciences, vol. 3, no. 4, pp. 745-752, 2012.

[29] N. Prabhu, D. T. Raj, K. Yamuna Gowri, S. Ayisha Siddiqua, and D. Joseph Puspha Innocent, "Synthesis of silver phyto nanoparticles and their antibacterial efficacy," Digest Journal of Nanomaterials and Biostructures, vol. 5, no. 1, pp. 185-189, 2010.

[30] R. Prasad, V. Kumar, and K. S. Prasad, "Nanotechnology in sustainable agriculture: present concerns and future aspects," African Journal of Biotechnology, vol. 13, pp. 705-713, 2014.

[31] V. S. Swamy and R. Prasad, "Green synthesis of silver nanoparticles from the leaf extract of Santalum album and its antimicrobial activity," Journal of Optoelectronic and Biomedical Materials, vol. 4, no. 3, pp. 53-59, 2012.

[32] A. Saxena, R. M. Tripathi, and R. P. Singh, "Biological synthesis of silver nanoparticles by using onion Allium cepa extract and their antibacterial activity," Digest Journal of Nanomaterials and Biostructures, vol. 5, no. 2, pp. 427-432, 2010.

[33] G. C. Schatz and R. P. van-Duyne, "Electromagnetic enhancement of surface-enhanced raman spectroscopy," in Handbook of Vibrational Spectroscopy, J. M. Chalmers and P. R. Griffiths, Eds., Wiley, New York, NY, USA, 2002.

[34] T. A. Davis, B. Volesky, and A. Mucci, "A review of the biochemistry of heavy metal biosorption by brown algae," Water Research, vol. 37, no. 18, pp. 4311-4330, 2003.

[35] A. B. G. Lansdown, "Silver. I: its antibacterial properties and mechanism of action," Journal of Wound Care, vol. 11, no. 4, pp. 125-130, 2002.

[36] I. Sondi and B. Salopek-Sondi, "Silver nanoparticles as antimicrobial agent: a case study on E. coli as a model for Gramnegative bacteria," Journal of Colloid and Interface Science, vol. 275, no. 1, pp. 177-182, 2004.

[37] R. M. Tripathi, D. Rana, A. Shrivastava, R. P. Singh, and B. R. Shrivastav, "Biogenic synthesis of silver nanoparticles using Saraca indica leaf extract and evaluation of their antibacterial activity," Nano Biomedicine and Engineering, vol. 5, no. 1, pp. 5056, 2013.

[38] J. R. Morones, J. L. Elechiguerra, A. Camacho et al., "The bactericidal effect of silver nanoparticles," Nanotechnology, vol. 16, no. 10, pp. 2346-2353, 2005.

[39] R. Prasad and V. S. Swamy, "Antibacterial activity of silver nanoparticles synthesized by bark extract of Syzygium cumini," Journal of Nanoparticles, vol. 2013, Article ID 431218, 6 pages, 2013.

[40] S. S. Birla, S. C. Gaikwad, A. K. Gade, and M. K. Rai, "Rapid synthesis of silver nanoparticles from Fusarium oxysporum by optimizing physicocultural conditions," The Scientific World Journal, vol. 2013, Article ID 796018, 12 pages, 2013.

[41] J. Xie, J. Y. Lee, D. I. C. Wang, and Y. P. Ting, "Silver nanoplates: from biological to biomimetic synthesis," ACS Nano, vol. 1, no. 5, pp. 429-439, 2007. 

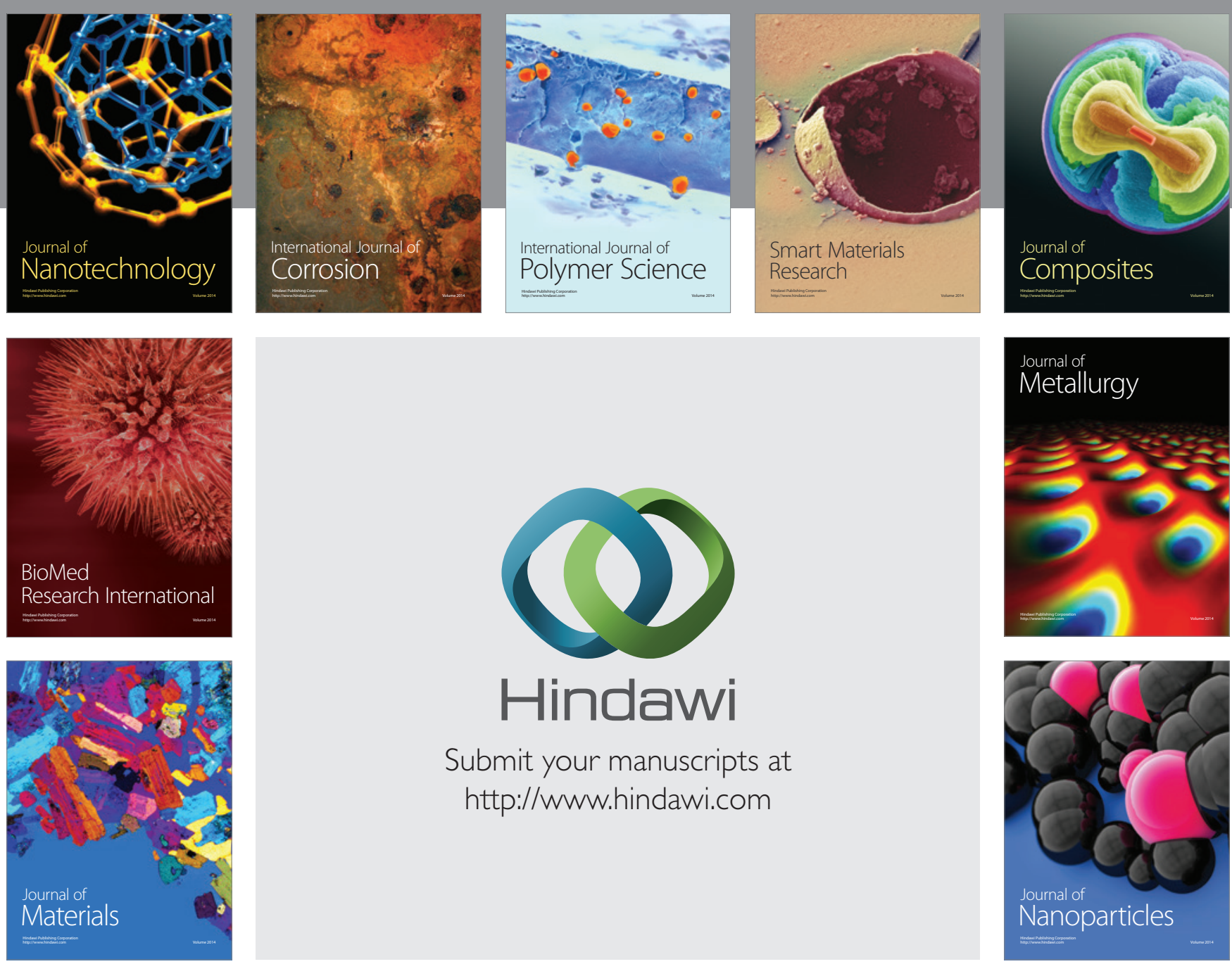

Submit your manuscripts at http://www.hindawi.com
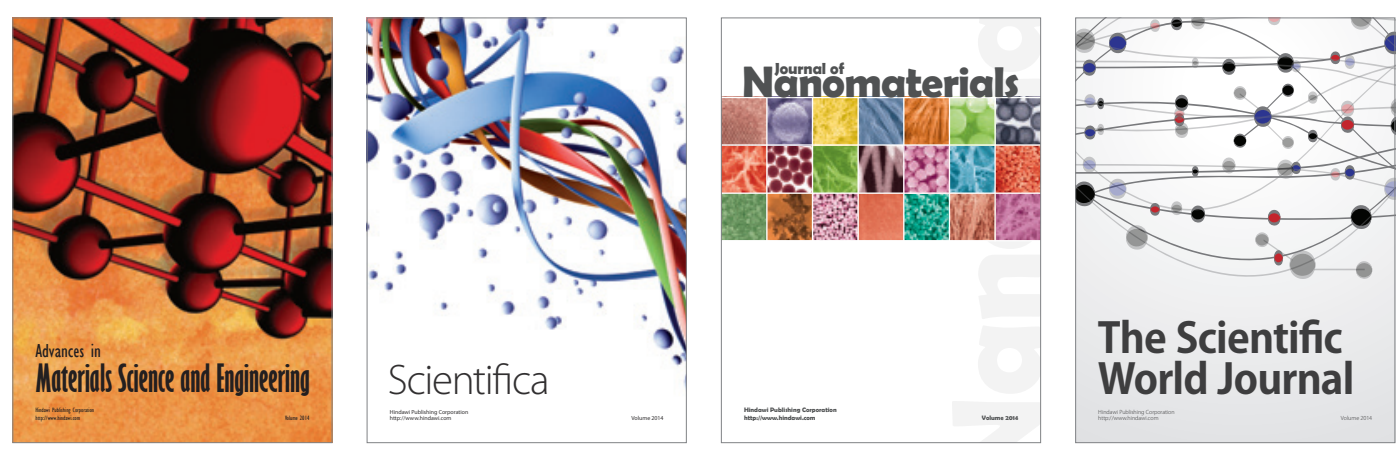

\section{The Scientific World Journal}
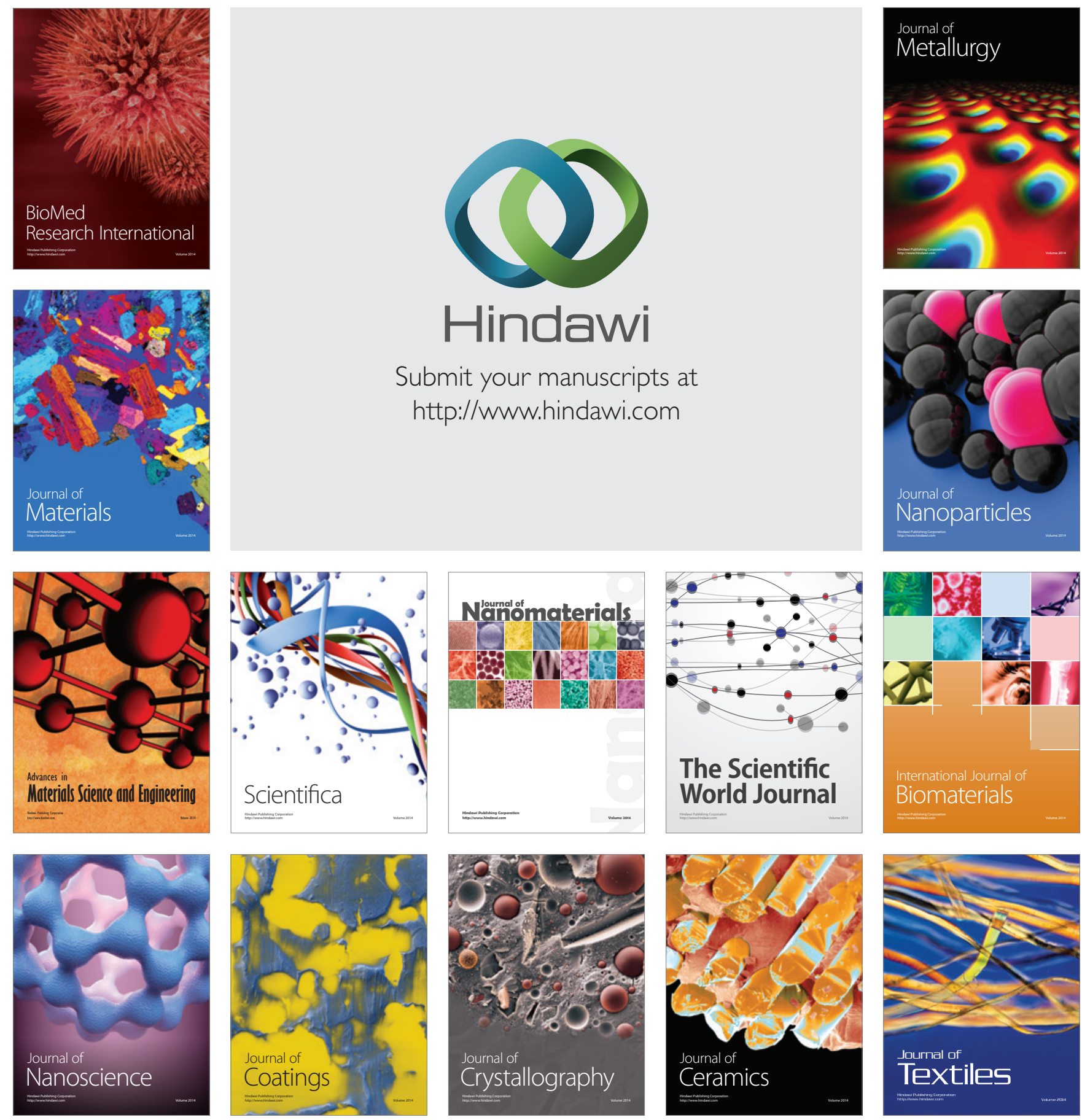